\title{
Design and Implementation of Low-cost Wideband Vivaldi Antenna for Ground Penetrating Radar
}

\author{
Baso Maruddani ${ }^{1,2}$, Efri Sandi ${ }^{1}$, and Muhammad Fadhil Naufal Salam ${ }^{1}$ \\ ${ }^{1}$ Electronics Vocational Education Program, Engineering Faculty, Universitas Negeri Jakarta, \\ Indonesia \\ ${ }^{2}$ DJA Institute, Jakarta, Indonesia
}

Corresponding Author:

Baso Maruddani

basomaruddani@unj.ac.id

Received: 11 January 2019

Accepted: 14 February 2019

Published: 25 March 2019

Publishing services provided by

Knowledge E

(c) Baso Maruddani et al. This article is distributed under the terms of the Creative Commons

Attribution License, which

permits unrestricted use and

redistribution provided that the

original author and source are

credited.

Selection and Peer-review under the responsibility of the 3rd ICTVET 2018 Conference Committee.

\section{Abstract}

Vivaldi antenna is one of the many types of antenna implemented on ground penetrating radar (GPR). Its characteristics are pointed radiation and wide bandwidth. This study aims to design an antenna used in GPR for non-destructive test application on a transportation to check the roadway material. This Vivaldi antenna has a wide bandwidth, $1 \mathrm{GHz}$ approximately, with the frequency range between $1 \mathrm{GHz}$ and $2 \mathrm{GHz}$. This Vivaldi antenna design is obtained by changing few parameters of common Vivaldi antenna to fulfill its design characteristics: low cost and wide bandwidth. The antenna size is $350 \mathrm{~mm} \times 300 \mathrm{~mm}$. The simulation result shows that there is a return loss below $-10 \mathrm{~dB}$ for $1-2 \mathrm{GHz}$ frequency range, and the lowest return loss at that frequency range is around $-35 \mathrm{~dB}$ on $1.4 \mathrm{GHz}$. This article also explains about the effect of tapered slot size changes to return loss value and frequency. When the antenna width is enlarged, the value of return loss is gets smaller in the lower frequency. Therefore, antenna bandwidth gets wider. The same happens when tapered slot size gets bigger value, the antenna working frequency switches into the lower frequency. It can be concluded that antenna bandwidth widening can be done by enlarging tapered length value and reducing tapered rate value.

Keywords: Vivaldi antenna, ground penetrating radar, optimization, low cost antenna, wide bandwidth

\section{Introduction}

Ground Penetrating Radar (GPR) is a technology that has been developed within 1520 years ago. The advancement involves theories, techniques, technology and also applications range. GPR is an imaging tool that uses electromagnetic waves to observe underground material. At the beginning of its emergence, GPR technology is used to detect natural materials, but as the theory and technique progress, GPR also is also used to detect unnatural materials such as asphalt, concrete, and even bridge structures. G OPEN ACCESS 
permittivity value. Simply talk, the GPR works by counting the amount of reflection and electromagnetic waves that fired on the surface [1].

There are two important parts in GPR: the antenna and the processing system to process a received / reflected signal. This paper focuses on the antenna used by GPR: Vivaldi antenna. Vivaldi antenna was first used by Gibson in 1979 with very wide bandwidth characteristics and directional radiation patterns [2]. Theoretically, Vivaldi antennas have infinite bandwidth, high gain, and linear polarization [3]. Figure 1 shows the concept of a Vivaldi antenna in the front view.

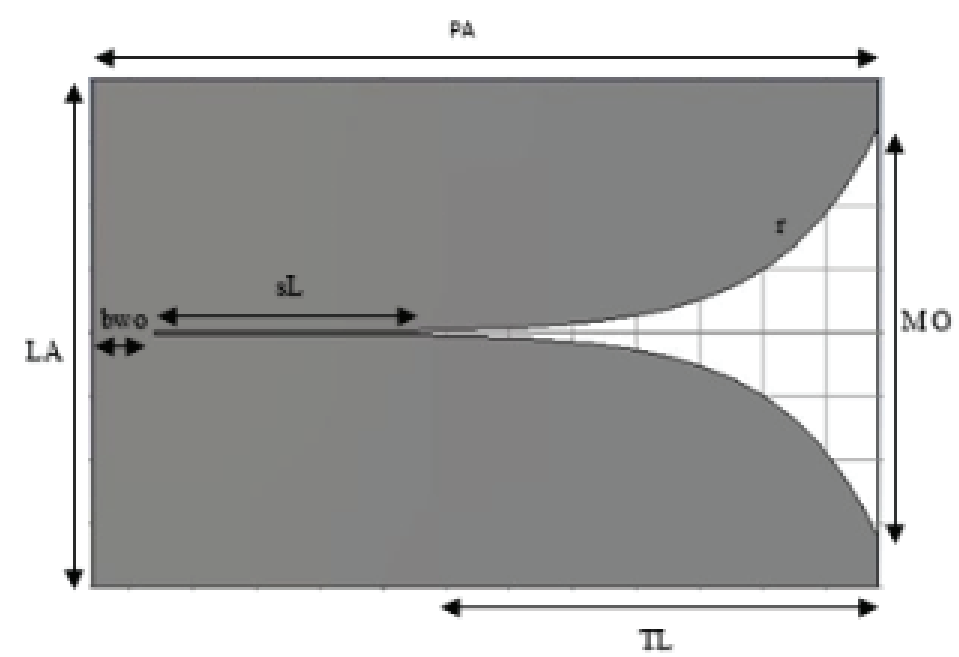

Figure 1: Vivaldi Antenna.

Dimension parameters of Vivaldi Antenna are antenna length (PA), antenna width $(\mathrm{LA})$, tapered length (TL), tapered rate ( $r$ ), slot-line length (sL), back-wall offset (bwo) and opening mouth (MO).The Vivaldi antenna included in the Exponential Tapered Slot Antenna (TSA) type.

\section{Methods and Equipment}

\subsection{Methods}

The development of the Vivaldi antenna on this paper begins by determining some antenna parameters to specify the initial antenna. The next step is making antenna modeling by using antenna simulation software based on parameters specified in the antenna dimension parameters. Antenna simulation is used to find out whether the antenna model meets antenna specifications for the Ground Penetrating Radar (GPR). After all antenna parameters are specified and simulated, the parameters are compared to the desired specification (frequency, return loss, VSWR). Frequency that use on GPR 
for non-destructive testing application is $700-2000 \mathrm{MHz}$. Our target for antenna frequency is $1-2 \mathrm{GHz}$, so that the antenna bandwidth is $1 \mathrm{GHz}$. If simulation result shows that antenna does not meet the specification yet, optimization is carried out. Optimization is done to achieve the specifications needed by learning various things, other literacy and also trial and error. Optimization is done by changing the values of the antenna dimension parameters. Each antenna dimension parameter has an effect for bandwidth antenna performance during this research period. Thus connecting between antenna width parameter and bandwidth of the Vivaldi antenna becomes one of the data results in this research.

The length (PA) and width (LA) of the antenna is determined by equation (1).

$$
\begin{gathered}
P A \approx \frac{c}{f \sqrt{\epsilon_{r}}} \\
L A \approx \frac{1}{2} \times \frac{c}{f \sqrt{\epsilon_{r}}}
\end{gathered}
$$

where PA is an antenna length, LA is an antenna width, $c$ is a speed of light, $f$ is the frequency, and $\epsilon r$ is a relative permittivity. In the design of Vivaldi's taper slot antenna, the dimensions of Tapered length and Tapered rate determines through the calculation using formula (3). The slope level of the taper slot of Vivaldi antenna greatly affects the gain, beam width and bandwidth of the TSA [3].

Tapered slot antennas have a curvilinear level based on exponential functions as in equation (3) where long tapered values was predetermined and the mouth opening value can be found by using formula (4)[4].

$$
\begin{gathered}
u= \pm s \times \exp ^{(r \times t)} \\
\pm \frac{M O}{2}= \pm \frac{s}{2} \times \exp ^{(r \times T L)}
\end{gathered}
$$

Air-coupled on GPR systems is used to evaluate and obtain information from the topside of the infrastructure (such as sidewalks or asphalt roads). Air-coupled antenna system operates on the frequency range 500 to $2500 \mathrm{MHz}$ and the middle frequency is on $1.0 \mathrm{GHz}$ where this frequency has an ability to penetrate ground 0.5 to 0.9 meters [5]. One of the advantages of an air-coupled antenna is that as the process is installed, data processing can be carried out at vehicle speeds of up to $100 \mathrm{~km} / \mathrm{h}$ which does not disturb the traffic around it.

Microstrip to the slot line transition is simply a feed technique by crossing the slot line with the microstrip [3]. This casting technique includes all types of electromagnetic 
couplings because the slot line and microstrip are separated by substrate elements. Stub is the distance between the midpoint of the microstrip and slot line meeting. Equation (5) is used to determine the wavelength by using a Microstrip pilot for slot line transitions. Table 2 shows Vivaldi antenna dimension parameter values after calculation and Figure 2 shows an initial design of Vivaldi antenna.

$$
\text { stubL }=0.25 \times \frac{c}{f_{c} \sqrt{\epsilon r}}
$$

TABLE 1: Parameters of Vivaldi antenna.

Parameters
Tapered Length
Tapered Rate
Mouth Opening
Stub Length
Slot line Length
Slot line Width
Antenna Length
Antenna Width
Cooper Thickness
Substrate Thickness
Backwall offset
Microstrip Width

\begin{tabular}{|c|}
\hline Symbols \\
\hline TL \\
\hline R \\
\hline MO \\
\hline stubL \\
\hline SL \\
\hline S \\
\hline PA \\
\hline LA \\
- \\
H \\
\hline bwo \\
\hline W
\end{tabular}

\begin{tabular}{|c|c|}
\hline Value \\
\hline $75 \mathrm{~mm}$ \\
\hline 0.0555 \\
\hline $73.22 \mathrm{~mm}$ \\
\hline $24.1 \mathrm{~mm}$ \\
\hline $74 \mathrm{~mm}$ \\
\hline $1.14 \mathrm{~mm}$ \\
\hline $150 \mathrm{~mm}$ \\
\hline $75 \mathrm{~mm}$ \\
\hline $0.035 \mathrm{~mm}$ \\
\hline $1.6 \mathrm{~mm}$ \\
\hline $1 \mathrm{~mm}$ \\
\hline $3.1 \mathrm{~mm}$
\end{tabular}

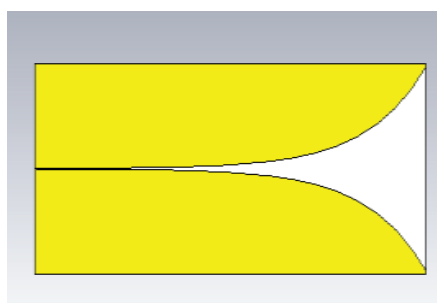

(a)

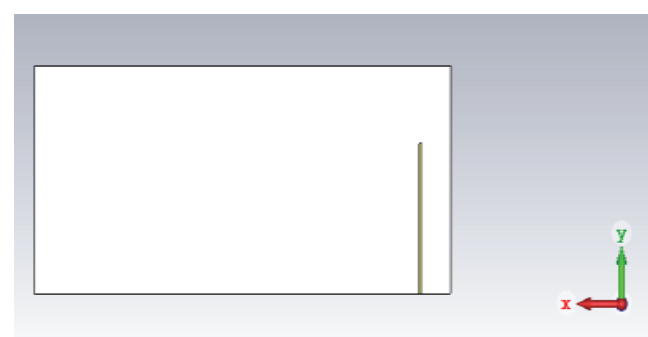

(b)

Figure 2: Initial design of Vivaldi antenna, front view (a), back view (b).

\section{Results}

The Vivaldi antenna design with dimension parameters results from the distribution calculation to determine the return loss and VSWR values in the working frequency range as shown in Figure 3.

Both graphs show that Vivaldi antenna does not have return loss and VSWR values according to specifications. Therefore optimization is done by changing the parameter 


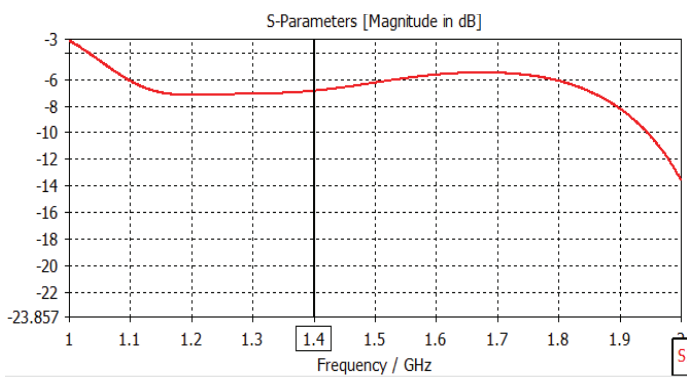

(a)

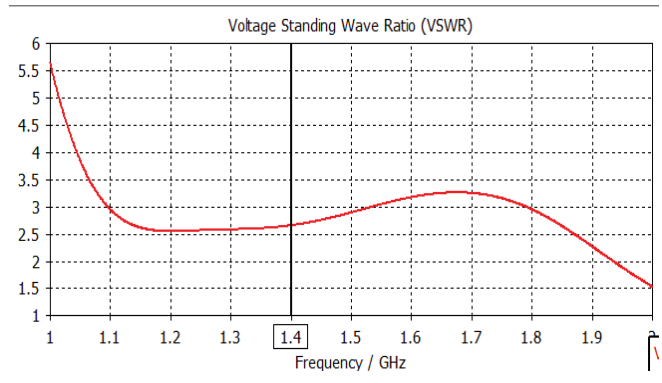

(b)

Figure 3: Simulation result of Vivaldi antenna at first, return loss (a), VSWR (b).

values of the dimensions of the antenna width, antenna length and tapered slot. The following Vivaldi antenna parameters after optimization are shown in Table 2 and simulation results with optimized parameters are shown in Figure 4. In Figure 4, return loss value is less than $-10 \mathrm{~dB}$ and VSWR value is between 1 and 2 .

TABLE 2: Parameters of Vivaldi antenna after optimization.

Parameters
Tapered Length
Tapered Rate
Mouth Opening
Stub Length
Slot line Length
Slot line Width
Antenna Length
Antenna Width
Cooper Thickness
Substrate Thickness
Backwall offset
Microstrip Width

\begin{tabular}{|c|c|}
\hline Symbols \\
\hline TL \\
\hline$R$ \\
\hline MO \\
\hline stubL \\
\hline SL \\
\hline S \\
\hline PA \\
\hline LA \\
\hline- \\
\hline H \\
\hline Bwo \\
\hline W
\end{tabular}

\begin{tabular}{|c|}
\hline Value \\
\hline $250 \mathrm{~mm}$ \\
0,022 \\
$278,95 \mathrm{~mm}$ \\
\hline $24,1 \mathrm{~mm}$ \\
\hline $99 \mathrm{~mm}$ \\
$1,14 \mathrm{~mm}$ \\
$350 \mathrm{~mm}$ \\
$300 \mathrm{~mm}$ \\
$0,035 \mathrm{~mm}$ \\
$1,6 \mathrm{~mm}$ \\
$1 \mathrm{~mm}$ \\
$3 \mathrm{~mm}$
\end{tabular}

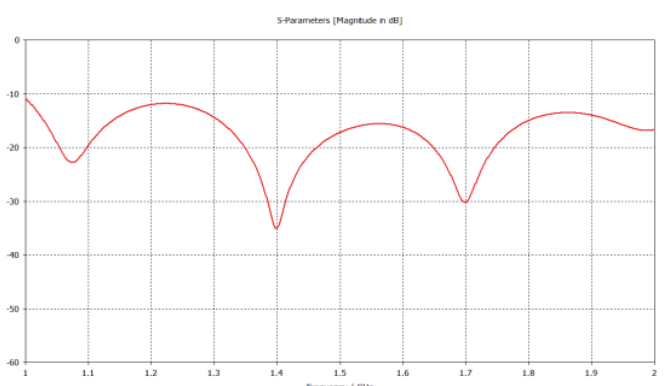

(a)

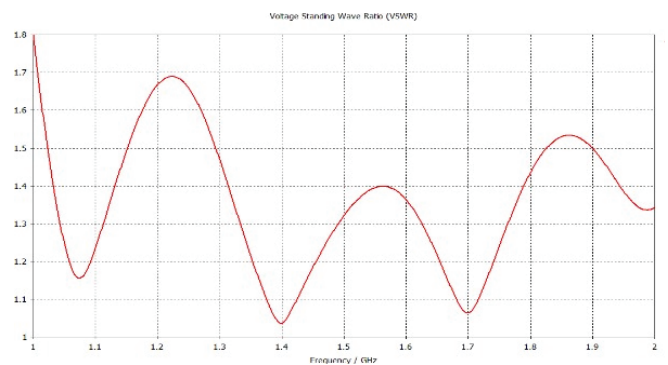

(b)

Figure 4: Vivaldi antenna simulation result after optimization, return loss (a) and VSWR (b). 


\subsection{Optimization process}

The optimization process is done by changing the antenna length value, antenna width and tapered rate value. For antenna widths, changes are made by making the antenna width larger. Figure 5(a) shows the change in the shape of the return loss graph for some antenna width values which are $75 \mathrm{~mm}$ (red), $100 \mathrm{~mm}$ (green), $125 \mathrm{~mm}$ (blue), 200 $\mathrm{mm}$ (orange) and $250 \mathrm{~mm}$ (pink). For antenna lengths, changes are made by increasing the antenna width value. Figure 5 (b) shows a graph of return loss against several values of the antenna length which are $200 \mathrm{~mm}$ (red), $250 \mathrm{~mm}$ (green), $300 \mathrm{~mm}$ (blue) and 350 $\mathrm{mm}$ (orange). For tapered rate values, tapered length values are made even greater, so the tapered rate becomes smaller. Tapered rate simulation is shown in Figure 6 .

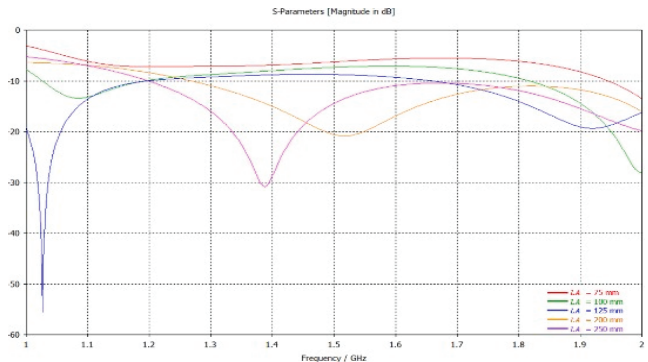

(a)

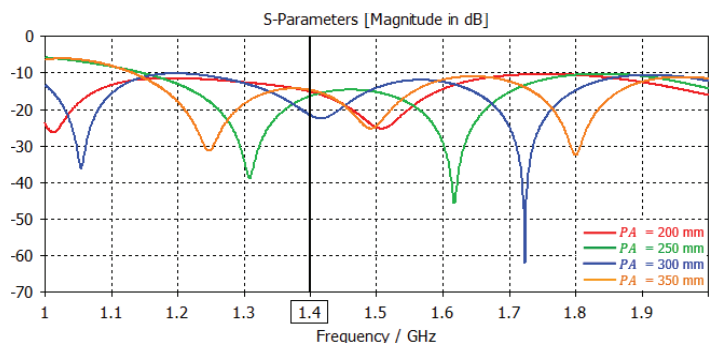

(b)

Figure 5: Return loss, antenna width shifting graph (a) and antenna length shifting graph (b).

TABLE 3: Tapered length and tapered rate optimization value.

Tapered length $(\mathbf{m m})$
75
100
150
250
300

\begin{tabular}{|c|}
\hline Tapered rate \\
\hline 0.0555 \\
\hline 0.04165 \\
\hline 0.0277 \\
0.022 \\
\hline 0.018 \\
\hline
\end{tabular}

\begin{tabular}{|c|}
\hline Color \\
\hline Red \\
\hline Green \\
\hline Blue \\
\hline Orange \\
\hline Pink \\
\hline
\end{tabular}

\section{Discussion}

Figure 5(a) shows when the antenna width value is enlarged, the graph gradually moves towards low frequency (return loss and VSWR). This causes greater bandwidth. Next, optimization is performed on the antenna length dimension parameters. Figure 5(b) shows return loss against several values of the antenna length: $200 \mathrm{~mm}$ (red), $250 \mathrm{~mm}$ (green), 300mm (blue) and $350 \mathrm{~mm}$ (orange). When the antenna length is enlarged, there is no significant change in the return loss and VSWR graphs to the working frequency range of the Vivaldi antenna. Antenna length value greater than the antenna width aims 


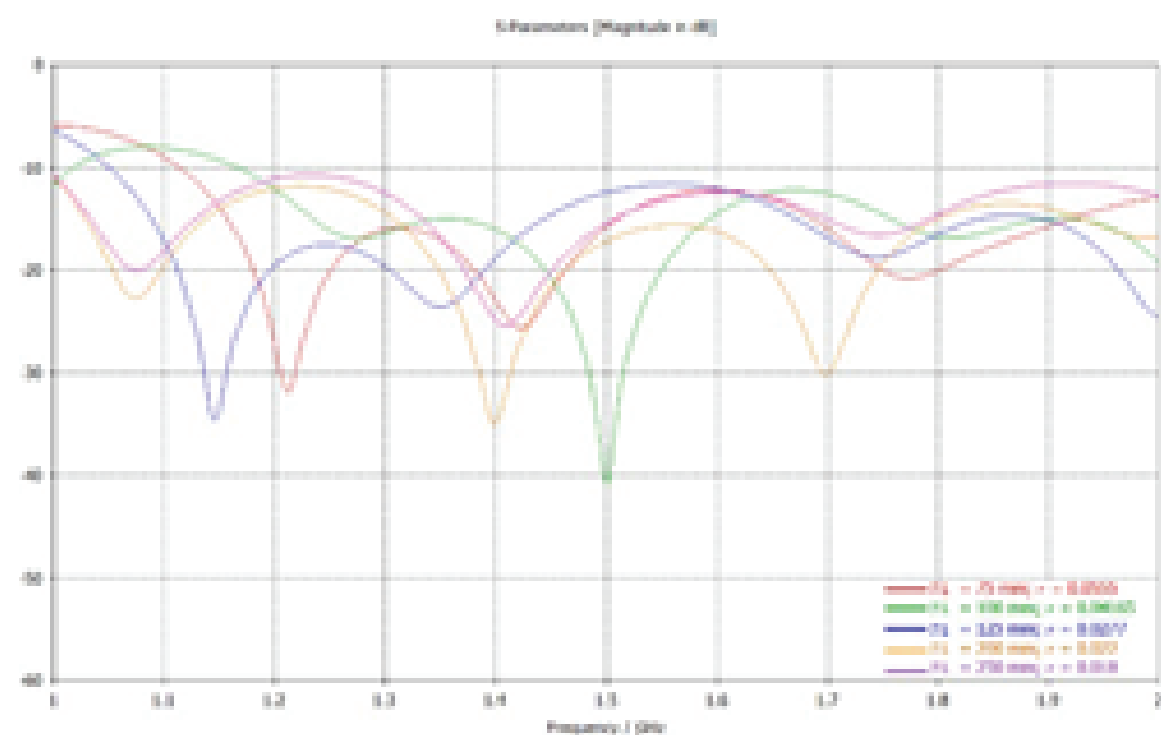

Figure 6: Return loss toward tapered slot value shifting.

to make the Vivaldi antenna still have a radiation pattern which is consistent with its characteristics.

Tapered slot optimization is done by changing two dimensional parameters, which are tapered length and tapered rate. Table 3 shows tapered length and tapered rate optimization values. In Figure 6, it can be seen that when the tapered slot, includes the tapered rate and tapered length values, is increased, the working frequency range of the Vivaldi antenna shifts towards the low frequency (return loss and VSWR). The result when tapered length value is enlarged and tapered rate value is reduced, the working frequency range widens. However, tapered slot optimization is limited by antenna width and antenna length because their dimension depend on the dimensions of the length and width of the Vivaldi antenna.

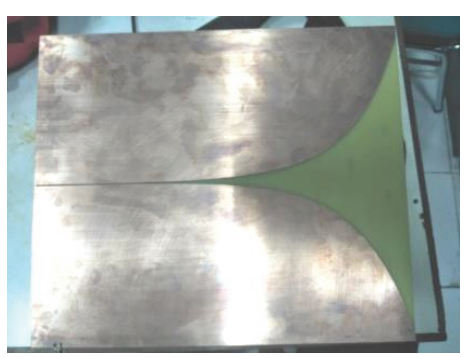

(a)

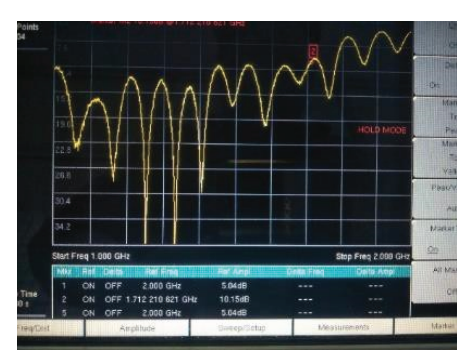

(b)

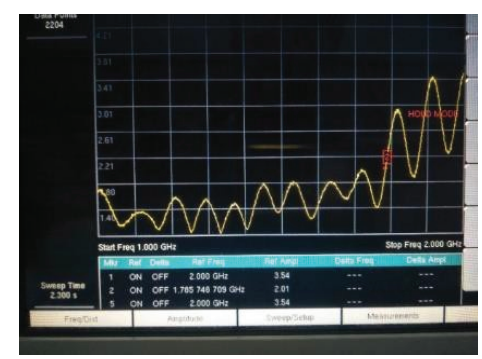

(c)

Figure 7: Fabricated antenna, the antenna (a), return loss measurement (b), VSWR measurement.

Furthermore, the antenna design is fabricated to determine its bandwidth by measuring it using a network analyzer. Figure 7(a) shows the fabricated Vivaldi antenna. The fabricated Vivaldi antenna bandwidth is measured using a network analyzer. Figures 
7(b) and 7(c) show the return loss graph and the VSWR of the fabricated Vivaldi antenna. Fabricated Vivaldi antenna shows a decrease in bandwidth and the working frequency whereas the fabricated Vivaldi antenna has a working frequency range from $1 \mathrm{GHz}$ to $1.7 \mathrm{GHz}$. The bandwidth decrease is caused some error on fabricated antenna that make differences between the dimensions of the Vivaldi antenna simulation and fabricated antenna parameters. Table 4 shows the comparison of the parameters of the Vivaldi antenna dimensions with the fabrication simulation. There are differences in the parameters of the mouth opening dimension, the width of the feed channel and the backwall offset. This causes differences in the results of fabricated and simulated antenna performance.

TABLE 4: Comparation between optimization and fabrication antenna parameters.

\begin{tabular}{|l|c|c|}
\hline Parameters & $\begin{array}{c}\text { Simulation } \\
\text { (optimization) }\end{array}$ & Fabrication \\
\hline Antenna Length & $350 \mathrm{~mm}$ & $350 \mathrm{~mm}$ \\
\hline Antenna Width & $300 \mathrm{~mm}$ & $300 \mathrm{~mm}$ \\
\hline Mouth Opening & $278,95 \mathrm{~mm}$ & $280 \mathrm{~mm}$ \\
\hline Feeder Width & $3 \mathrm{~mm}$ & $2 \mathrm{~mm}$ \\
\hline Backwall Offset & $1 \mathrm{~mm}$ & $1,5 \mathrm{~mm}$ \\
\hline
\end{tabular}

\section{Conclusion}

The design of the Vivaldi antenna for the Ground Penetration Radar is carried out starting from the literature study, determining antenna specifications, designing and optimizing the shape of Vivaldi antenna on the antenna simulator application and antenna fabrication so that the bandwidth can be measured.

This Vivaldi antenna with dimension $350 \times 300 \mathrm{~mm}$ has a working frequency range from $1 \mathrm{GHz}$ to $1.7 \mathrm{GHz}$ with return loss values is less than $-10 \mathrm{~dB}$ and VSWR value is between 1 and 2. The fabricated Vivaldi antenna has decreased bandwidth from the simulation results which has bandwidth $1 \mathrm{GHz}$ with a working frequency range from $1 \mathrm{GHz}$ to $2 \mathrm{GHz}$. However, the fabricated Vivaldi antenna can be used on GPR for Non-Destructive Testing Highway antennas, which the general frequency for NonDestructive Testing Highway is $700 \mathrm{MHz}-2 \mathrm{GHz}$. 


\section{Acknowledgement}

The authors would like to express their gratitude to the Dean of the Engineering Faculty, Universitas Negeri Jakarta, for the contribution and support to the research.

\section{Conflict of Interest}

The authors have no conflict of interest to declare.

\section{References}

[1] H. M. Jol, Ground Penetrating Radar Theory and Applications. Oxford: Elsevier Science, 2008.

[2] P. J. Gibson, "The Vivaldi Aerial," in 1979 9th European Microwave Conference, 1979, pp. 101-105.

[3] R. Rajaraman, Design Of a Wideband Vivaldi Antenna Array for the Snow Radar. University of Kansas, 1999.

[4] Y. Erdogan, Parametric Study and Design of Vivaldi Antennas and Arrays. Ankara, Turki: Middle East Technical University, 2009.

[5] T. Hariyadi and M. Mukhidin, "Studi Parametrik Antena Vivaldi Slot dengan Pencatuan Mikrostrip," in Seminar Nasional Teknologi (SENATEK) 2015, 2015, pp. 397-403. 